\title{
A Study on the Main Determination of Mortgage Risk: Evidence from Reverse Mortgage Markets
}

\author{
Chien-Chiang Lee ${ }^{1}$, Kuo-Shing Chen ${ }^{1} \&$ David So-De Shyu ${ }^{2}$ \\ ${ }^{1}$ Department of Finance, National Sun Yat-sen University, Kaohsiung, Taiwan \\ 2 Takming University of Science and Technology, Taipei City, Taiwan \\ Correspondence: Kuo-Shing Chen, Department of Finance, National Sun Yat-sen University, 70 Lienhai Rd., \\ Kaohsiung 80424, Taiwan. E-mail: d974030003@student.nsysu.edu.tw
}

Received: February 17, 2015

Accepted: March 11, 2015

Online Published: March 31, 2015

doi:10.5430/ijfr.v6n2p84

URL: http://dx.doi.org/10.5430/ijfr.v6n2p84

\begin{abstract}
The main determination of mortgage risk factors is undoubtedly related to the housing price .In this article, we employ threshold GARCH process in practical analysis, to capture the house price dynamic on the logarithm return. This study also estimates the housing price volatility in the presence of stationary variance property from the threshold GARCH model and its implied volatility can serve as a benchmark for the pricing reverse mortgage derivatives. Our results have important implications for hedging risk of reverse mortgages. To our best knowledge, this paper is the first study employing Poisson Regression approach to look at the housing prices risk of reverse mortgage incorporated with its number of loans.
\end{abstract}

Keywords: reverse mortgages, poisson regression, threshold GARCH, housing price process

\section{Introduction}

After 2008 financial crisis, in circumstances where a loan balance is greater than the actual property value, the Federal Housing Administration (FHA) insures the lender against any shortfall. The FHA's ability to provide this insurance is paid through mortgage premiums at loan origination and a monthly interest rate add-on. HECM is the generally applied acronym for a Home Equity Conversion Mortgage, which also stands for a reverse mortgage (hereafter RM), created by and regulated by the U.S. Government Department of Housing and Urban Development (HUD). A HECM is a loan issued by a private bank or insurance corporation, but insured by the Federal Housing Administration, which is part of HUD. The borrower is charged an insurance fee of $1.25 \%$ of the loan balance each year. The insurance purchased by this fee protects the mortgage borrower have two flaws: (1) if the home's value upon sales is not enough to cover the loan balance; and (2) if and when the lender is unable to make a payment. In the former case, the government insurance fund would pay off the remaining balance. The HECMs make up $99 \%$ of the reverse mortgages offered in America at present. Reverse mortgages are a highly risky financial product with high uncertainty. The existing literatures on risk analysis about the mortgages area have three brief flaws.

First, there have been many theoretical and empirical discussions on reverse mortgage loans. Prior researches have mainly suggested on the risks borne by the suppliers of reverse mortgage products or the risk associated with the American reverse mortgage system with public guarantees (e.g., Quercia, 1997, and Shiller and Weiss, 1999). These studies have been conducted largely for analyzing the risk management plans for the guarantees relating to reverse mortgages. To identify the adequacy of the main variables of the current reverse mortgage model, Lee et al. (2012) reviewed the actuarial model by analyzing the risk associated with such variables. They verified the implied market risk in the valuation of reverse mortgages associated with tenure payments model by applying housing prices and a stochastic interest rate generator model. By proposing credit security measures to mitigate such risks, they provided an alternative method for eliminating market risk.

The second is that the threshold GARCH (TGARCH) model can capture asymmetric volatility. This more flexible volatility can respond to the positive and negative shocks. Moreover, Awartani and Corradi (2005) employed daily S\&P-500 Composite Price Index and pointed out supportive evidence that GARCH models allowed for asymmetries in volatility produce more accurate volatility predictions. In this study, we will focus on the TGARCH model for the simulation results. Another important issue in the GARCH option pricing model is considered for pricing purposes 
under the equivalent martingale measure. Therefore, it is well known the market is incomplete that there are an infinite number of risk neutral measures under which one can price derivatives in the GARCH framework. Therefore, this leads to more than one possible fair prices, all of which are consistent with the absence of arbitrage opportunities. The traditional approach for derivative pricing in the GARCH framework setup is under the Risk Neutral Valuation Relationship (RNVR) pioneered by Duan (1995).

The third is previous papers addresses the method of transferring and financing the risks associated with these products through the form of modeling dynamics process. The underlying asset of HECM product is the mortgaged asset value. But, the mortgaged property is seldom traded in the market and is impossible to collect historical data about individual mortgaged property, which increases difficulties on the pricing topic. Therefore, we can simplify this issue in terms of the house price indices that reflect the fluctuation in resident property price. In recent years, researchers choose house price index (HPI) data to fit adequate stochastic process (e.g. Chen et al., 2010, Li et al., 2010). In previous literatures, some studies capture house price process by dynamic process. Case and Shiller (1989) employed repeat transaction indices to examine whether housing markets in United States are efficient and forecasting housing prices. Crawford and Fratantoni (2003) compared to the performance of three types of univariate time series models in housing price and figured out that ARIMA models generally perform better in out-of-sample forecasting.

Our study extends the growing literature on the pricing and risk management of reverse mortgages (see, e.g., Alai et al., 2014; Hosty et al., 2008). The contributions of this research are twofold. First, for model comparison, we employ a Threshold Generalized Autoregressive Conditional Heteroskedastic (TGARCH) model for housing price dynamics, and consider the jump effect on housing prices in further valuation of RMs. Second, we use Poisson regression and Tobit model for the number of mortgages with mortgage crossover risk, interest rates and appraised property values.

The remaining of the paper is organized as follows: Section 2 we provide a dynamic process to model the house price depreciation risk. Section 3 presents the number of reverse mortgages focusing on housing price major risks approach, Section 4 reports data and the empirical results, and the last section draws conclusion.

\section{The Model for the Risk of RMs}

\subsection{Insurer's Risks}

Federally insured HECMs have potentially important implications to play an important part in enabling financial security system for senior homeowners. The FHA must collect all the insurance premiums and reverse mortgage lenders are allowed to assign the loan to FHA when the loan balance equal or exceed to the adjusted mortgage value. FHA takes over the loan and pays an insurance claim to lenders covering their losses. So lenders are effectively transfering the collateral risk to FHA (Alai et al. 2014).

\subsection{Optimal Collateralization of Risk Transfer}

Reverse mortgages are different from traditional forward mortgages in the way pattern that the outstanding loan balance grows owing to interest accruals, principal advances, and other loan charges over the life of the loan. The outstanding balance may grow to exceed the collateral value at the termination time because of multiple risks. Major risks in reverse mortgages constitute three main factors to be expressed as:

Crossover Risk: If the decrease in house price or homeowers live longer than expected, the principal advances and interest accruals will continue, which may cause the outstanding balance exceeding the sale proceeds of the property.

Housing Price Depreciation Risk: The uncertainty associated with housing price depreciation is another risk factor we need to take into consideration collateral risk. If the house price remains sluggish or grows at a lower rate than anticipated, the balance outstanding on a loan at maturity may exceed the proceeds from the sale of the collateral. Lenders or their insurers may suffer from the losses.

Interest Rate risk: The interest rate variation grants additional uncertainty on reverse mortgage providers.

\subsection{Housing Price Process Model}

Consider a discrete time economy with a risk-free asset and a risky asset. We suppose that there is a complete filtered probability space $\sigma\left(\Omega, \mathcal{F},\left\{\mathcal{F}_{\mathrm{t}}\right\}, \mathcal{P}\right)$ to model uncertainty. $\mathcal{P}$ is the historical (physical) measure and $\mathcal{F}=\left\{\mathcal{F}_{\mathrm{t}}\right\}, t=0$, $1, \ldots T(T<1)$, is a filtration, or a family of increasing $\sigma$-field information sets, representing the resolution of uncertainty based on information generated by the market prices up to and including time t. We assume $\mathcal{F}_{0}$ $=\sigma\{0, \Omega\}$ and $\mathcal{F}_{\mathrm{t}}=\mathcal{F}$. We assume the following GARCH (p,q) model for the $\log \operatorname{return} R_{t}=\log \left(H_{t} / H_{t-1}\right)$, where $H_{t}$ is the housing prices at time t. The TGARCH model was proposed by Zakoian (1994) and, the 
conditional variance for TGARCH model treats the conditional standard deviation as a linear function of shocks and lagged standard deviations. This study proposed the following TGARCH $(1,1)$ models:

$$
\sigma_{t}^{2}=\omega_{0}+\left(\alpha_{1}+\gamma_{1} I_{t-1}\right) \varepsilon_{t-1}^{2}+\beta_{1} \sigma_{t-1}^{2}
$$

where $\varepsilon_{t}$ error term, $\varepsilon_{t} / \Omega_{t-1} \sim N\left(0, \sigma_{t}^{2}\right), \Omega_{t-1}$ denoted $\mathrm{t}-1$ period information, $\omega_{0}>0, i=1,2, \ldots, \mathrm{q} \cdot I_{t-1}$ represent indicator function as follows:

$$
I_{t-i}=\left\{\begin{array}{l}
1, \text { if } \varepsilon_{t-i}<0 \\
0 \text { otherwise }
\end{array} \mathrm{i}=1,2, \quad, p\right.
$$

Here $\gamma$ is the positive parameter and the stationary covariance property requires $\left(\alpha_{1}+\beta_{1}+\frac{\gamma_{1}}{2}\right)<1$. Depending on whether $\varepsilon_{t-1}$ is above or below zero, $\varepsilon_{t-1}^{2}$ have different effects on the conditional variance $\sigma_{t}^{2}$. If there is good news, $\varepsilon_{t-1} \geq 0$ such that $I_{t-1}=0$, the total effect is $\alpha_{1} \varepsilon_{t-1}^{2}$ on the next period conditional variance. If there is bad news, $\varepsilon_{t-1}<0$ such that $I_{t-1}=1$, the total effect is $\left(\alpha_{1}+\gamma\right) \varepsilon_{t-1}^{2}$ on the next period conditional variance. So bad news will have larger impact on the conditional variance. However this model different from other models, In a GARCH context, as note above, Duan (1995) provides a locally risk-neutral valuation relationship (LRNVR). A pricing measure $Q$ is said to satisfy the LRNVR if measure $Q$ is mutually absolutely continuous with respect to measure $\mathcal{P}$ and satisfies the following conditions:

$$
\begin{gathered}
E^{Q}\left(\frac{H_{t}}{H_{t-1}} / F_{t-1}\right)=e^{r} \\
\operatorname{Var} Q\left[\log \left(\frac{H_{t}}{H_{t-1}}\right) / F_{t-1}\right]=\operatorname{Var}^{P}\left[\log \left(\frac{H_{t}}{H_{t-1}}\right) / F_{t-1}\right]
\end{gathered}
$$

almost surely with respect to measure $\mathcal{P}$.

Duan (2006) et al. point out the estimated coefficient of model even if the condition is in line with the previously described. There are still impossible to obtain an approximate variance. It is due to estimate the asymmetry fluctuation of the underlying asset, indicator function will be additional condition in the model. It's necessary to add some of conditions obtaining a stationary variance. According to the Duan (2006) et al. who described under the situation without consideration risk premium, the stationary variance of TGARCH $(1,1)$ model is calculated as follows:

$$
\sigma_{H}^{2}=E\left(\sigma_{t}^{2}\right)=\frac{\omega_{0}}{1-\left(\alpha_{1}+\beta_{1}+\frac{\gamma_{1}}{2}\right)}
$$

Proof see Appendix.

For the TGARCH $(1,1)$ process, the stationary condition constraint is shown in equation (5). The volatility underlying asset prices have not fluctuated abnormal volatility in the market and simulated data, therefore would not produce frequently greater residual so that its variance possess the convergence value (i.e. stationary variance).

\section{Methodology}

As noted above, borrower longevity, interest rates and future property values are the primary sources of collateral risk for the reverse mortgage lender. To capture the censored characteristics of the number of RM loans, we employ the Poisson regression and Tobit model for the number of mortgages. The Poisson distribution is a discrete 
probability distribution that expresses the probability of a number of events occurring in a fixed period, if the events occur at a known average rate and independent of the time since the last event (see Winkelmann, 2003). It is mainly used for deal count data with discrete type. If assumption that the random variable $y$ is the number of mortgages, and follows Poisson distribution, probability density function can be expressed as:

$$
P_{r}(Y=y)=\frac{e^{-u} u^{y}}{y !}, y=0,1,2
$$

Where $\boldsymbol{y}$ is the count values, $\mathbb{X}$ is the regressors .Thus, expectations will change with regressions $\mathbb{X}$ variation, and $\beta$ represent the estimated vector parameters. This model leads to the following property $E(Y)=\operatorname{Var}(Y)=u$. Also, when estimating a Poisson regression model it is usual to have an exponential mean parameterization, so that $u_{j}=\exp \left[\mathbb{X}_{j}^{\prime} \beta\right]$ where $j$ refers to each of the $N$ observations and $\mathbb{X}$ is a vector of regressors, which is stated below:

$$
\mathbb{X}_{j}=\left[H_{A}, \text { INIT_PRNCPL_LMT }, i\right]
$$

$\mathbb{X}_{j}$ is a vector of factors that influence entry and $\beta$ is a vector of estimated coefficients, where contains information about housing prices, loan interest rates and crossover characteristics (the initial principal limit). Where INIT_PRNCPL_LMT is the initial principal limit (IPL) which means the initial loan amount that may be extended to a borrower by a lender. It is determined by the age of the borrower, the expected interest rate, and the adjusted property value. Specifically, initial principal limit reflects the crossover risk, loans status which it represents the mortgage credit in RM markets. Where $i$ is loan interest rates variable for the number of loans, and $H_{A}$ denotes housing prices is considered as price depreciation risk. A Poisson estimator is appropriate for the analysis of the number mortgage loans and, in other applications (Greene, 2011).

\section{The Empirical Analysis}

In this section, we first evaluate the performance of the estimated TGARCH model parameters from housing prices data and examine the convergence of the approximation methods.

\subsection{Sample Selection}

To select our sample, data consist of two flaws.

\subsubsection{The Housing Price Data}

To test housing price dynamics empirically, we employ monthly observations of the U.S. national average prices of previously occupied houses for conventional single-family mortgages as a proxy for housing prices, using data from the Federal Housing Finance Agency (http: //www.fhfa.gov). In this study, we select previously occupied home prices as the proxy for housing prices because a reverse mortgage loan gets repaid through the proceeds of the sale of the mortgaged property. We examine the monthly average of the prices of all homes with adjustable-rate mortgages and contain the term on conventional single-family mortgages and the monthly national average of all house prices in the United Sates. Our sample period is from January 1989 to December 2012, leading to 288 observations for each variable. It is considered a bellwether for American economy.

\subsubsection{The RMs Data}

In addition, we also used the RMs data each even year from 1989 through December 2007 and the years from January 2008 to October 2010.We obtain RMs data provided by HUD. (Note 1) Finally, filter out the 24,170 loan data. (Note 2) The information to data, the distribution of borrower's age is shown in Figure 1.The time series exhibit some interesting patterns. First, there exists substantial cross-sectional difference among elder borrower; and second, due to 2008 financial crisis, there is a clear structural change in the number of RM loans for the two sub-periods before and after 2007, which we have chosen to divide our sample. The first period, from January 1989 to Dec 2007, is characterized by lower RM loans. In the second sub-period from Jan 2008 to Oct 2010, the dynamics and levels of the default risk change dramatically. The number of RM loans increase considerably with much higher volatility.

\subsection{Empirical Results and Discussion}

Based on the empirical HPI data, Chen et al (2010) investigated HECM program and employed the nationwide house price index (HPI) to capture the house price dynamics. They choose the same house price data and extend the data period from the first quarter of 1975 to the first quarter of 2009. Let $R_{t}$ denote the log-return for house price index, which is defined as $R_{t}=\log \left(H_{t} / H_{t-1}\right)$. Li et al. (2010) also indicate three important habitudes for the house price dynamics in the U.K, which are volatility clustering, leverage effects and autocorrelation. Based on the nationwide HPI in the U.S., the presence of aleverage effect seems less likely to exist. For the purpose of this study, however, we principally focus on the important implication of uncertainties on housing price dynamics of reverse mortgages. 


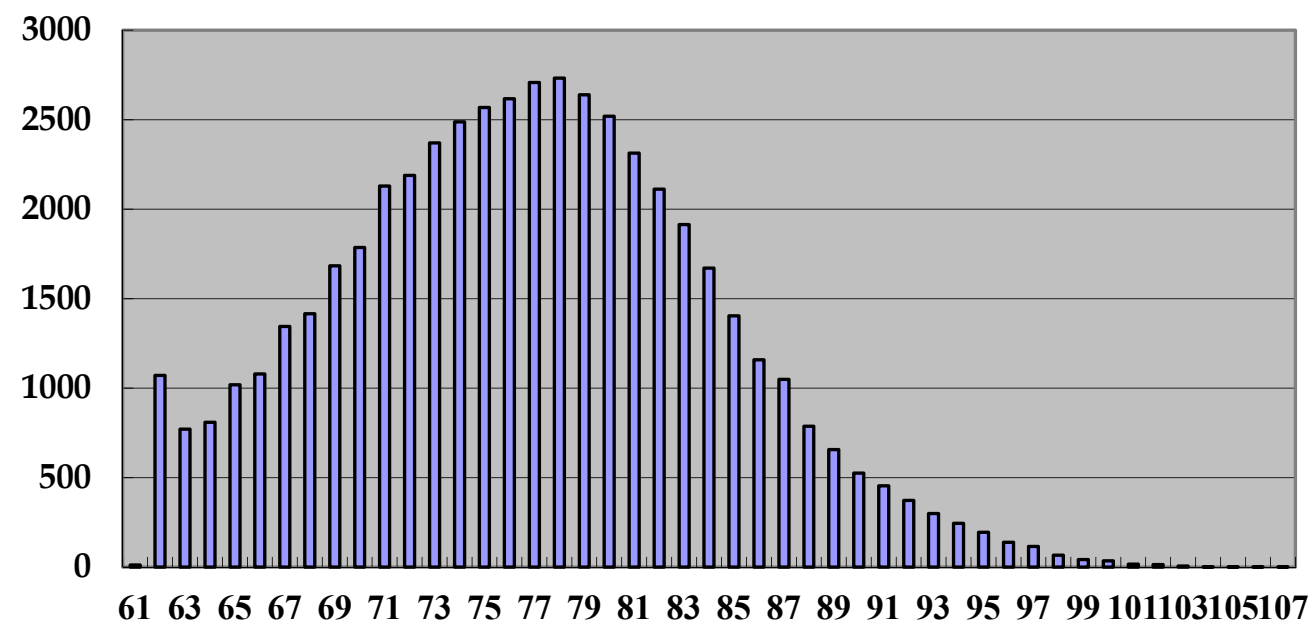

Figure 1. Distribution of borrower's age

The loan value is determined by the borrower's age, the interest rate, and the home's value. In this research, we specifically focus on the loans numbers of RMs (Note 3) have important implication for the determination of risk factor for the interest rate on the loan, the house price variation, and the termination risk. We employ the Poisson regression and Tobit model to explain the risk factor for the loan numbers on RMs. The estimated parameters present in panel (A), (B) of Table1. It is shown that the numbers on RMs are positively associated with housing price, and initial principal limit, but are negatively associated with loan interest rate after 2007. Thereafter, note that Figures 2 , 3 and we use the Q-Q plot quantile test of the residuals to test Poisson against Tobit regression, and the Tobit model is apparently provides a significant improvement with respect to the Poisson model.

Based on the recent studies, the classes of the GARCH models perform better than the traditional Black-Scholes model and the TGARCH models outperform the standard GARCH model in the context option pricing. As a result, we use the TGARCH model in our empirical studies. Following the practice in Duan (1995), the Black-Scholes option price and terminal stock price are computed using the stationary variance $\omega_{0}\left(1-\alpha_{1}-\beta_{1}-\gamma_{1} / 2\right)^{-1}$ of the TGARCH model in the Black-Scholes closed-form formula.We first construct an adequate $\operatorname{TGARCH}(1,1)$ model for the conditional variance of the log-return for house price for single-family mortgages series. The models are tested against misspecifications applying the tests in Lundbergh and TerÄasvirta (2002) to the GARCH model.

Table 1. Poisson Regression and Tobit model for the loans numbers on RMs (Dependent variable: the loans numbers on RMs)

\begin{tabular}{|c|c|c|c|c|}
\hline \multirow{2}{*}{$\begin{array}{r}\text { Panel (A) pr-2007 } \\
\text { variable }\end{array}$} & \multicolumn{2}{|c|}{ Poisson Count } & \multicolumn{2}{|c|}{ Tobit model } \\
\hline & Coefficient & Prob. & Coefficient & Prob. \\
\hline $\log$ (INIT_PRNCPL LMT) & $\begin{array}{c}0.345^{* * *} \\
(2026.787)\end{array}$ & 0.000 & $\begin{array}{c}0.196^{* * *} \\
(10.281)\end{array}$ & 0.000 \\
\hline$i$ & $\begin{array}{c}-0.036^{* * *} \\
(-1550.949)\end{array}$ & 0.000 & $\begin{array}{l}-0.034^{* * *} \\
(-11.485)\end{array}$ & 0.000 \\
\hline $\log \left(\mathrm{H}_{\mathrm{A}}\right)$ & $\begin{array}{c}-0.757^{* * *} \\
(-4928.967)\end{array}$ & 0.000 & $\begin{array}{l}-0.586^{* * *} \\
(-35.568)\end{array}$ & 0.000 \\
\hline $\mathrm{C}$ & $\begin{array}{c}15.301^{* * *} \\
(17164.04)\end{array}$ & 0.000 & $\begin{array}{c}5.99^{* * *} \\
(50.268) \\
\end{array}$ & 0.000 \\
\hline Log likelihood & $-2.36 \mathrm{E}+08$ & & -33114.94 & \\
\hline Akaike info criterion & 17093.19 & & 2.4 & \\
\hline Prob(LR statistic) & & 0.000 & & 0.000 \\
\hline
\end{tabular}

Panel (B) after post 2007 


\begin{tabular}{ccccc}
\hline $\log ($ INIT_PRNCPL_LMT $)$ & $0.0005^{* * *}$ & 0.000 & 0.002 & 0.861 \\
& $(6.48)$ & & $(0.175)$ & \\
\hline$i$ & $-0.003^{* * *}$ & 0.000 & $-0.012^{* * *}$ & 0.000 \\
& $(-225.301)$ & & $(-6.296)$ & \\
\hline & $0.005^{* * *}$ & 0.000 & $0.022^{* *}$ & 0.0458 \\
$\log \left(\mathrm{H}_{\mathrm{A}}\right)$ & $(71.304)$ & & $(1.966)$ & \\
\hline $\mathrm{C}$ & $11.512^{* * *}$ & 0.000 & $4.127^{* * *}$ & 0.000 \\
& $(25374.09)$ & & $(57.98)$ & \\
\hline Log likelihood & $-2.36 \mathrm{E}+08$ & & -16652.67 & \\
\hline Akaike info criterion & 17093.19 & & 1.378 & 0.000 \\
\hline Prob(LR statistic) & & 0.000 & & \\
\hline
\end{tabular}

Notes:

1. Pr-2007: $\mathrm{N}=27,598 ;$ Post 2007: $\mathrm{N}=24,170$.

2. Poisson Count (Quadratic hill climbing), Numbers in parentheses are t-Statistic.

$3 .^{*} \mathrm{p}<0.05 * * \mathrm{p}<0.01 * * \mathrm{p}<0.001$.

4. Eq. (6) can also be written as $f(y)=P_{r}(y ; \beta)=\frac{e^{-\mu(x, \beta)} \mu(x, \beta)^{y}}{y !}$. The numbers of RMs arising from disjoint time intervals are independent.
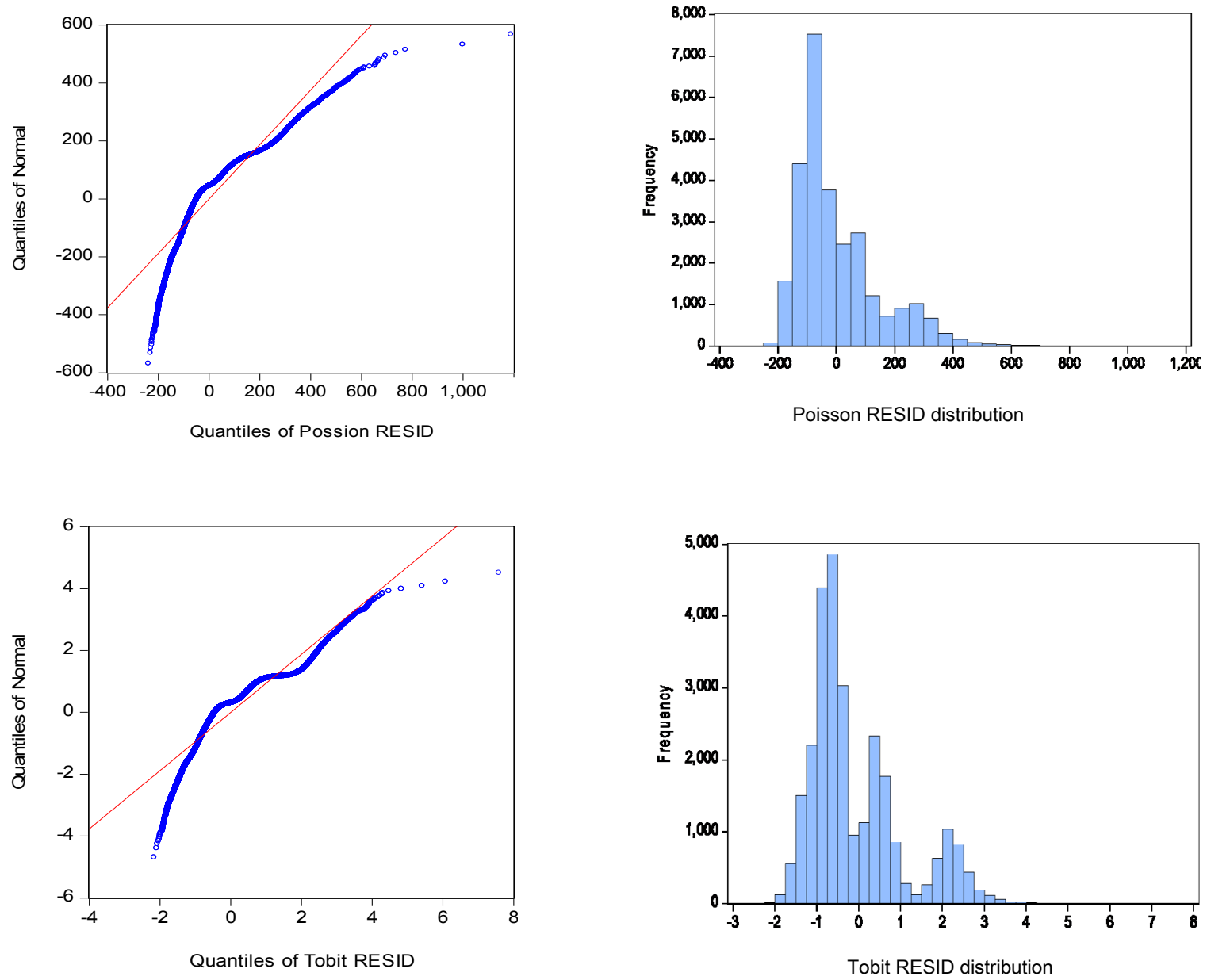

Figure 2. Q-Q plot and Histogram of the residuals under Poisson and Tobit methodology

Period 1. (Pr-2007 i.e. before the end of 2007.) 

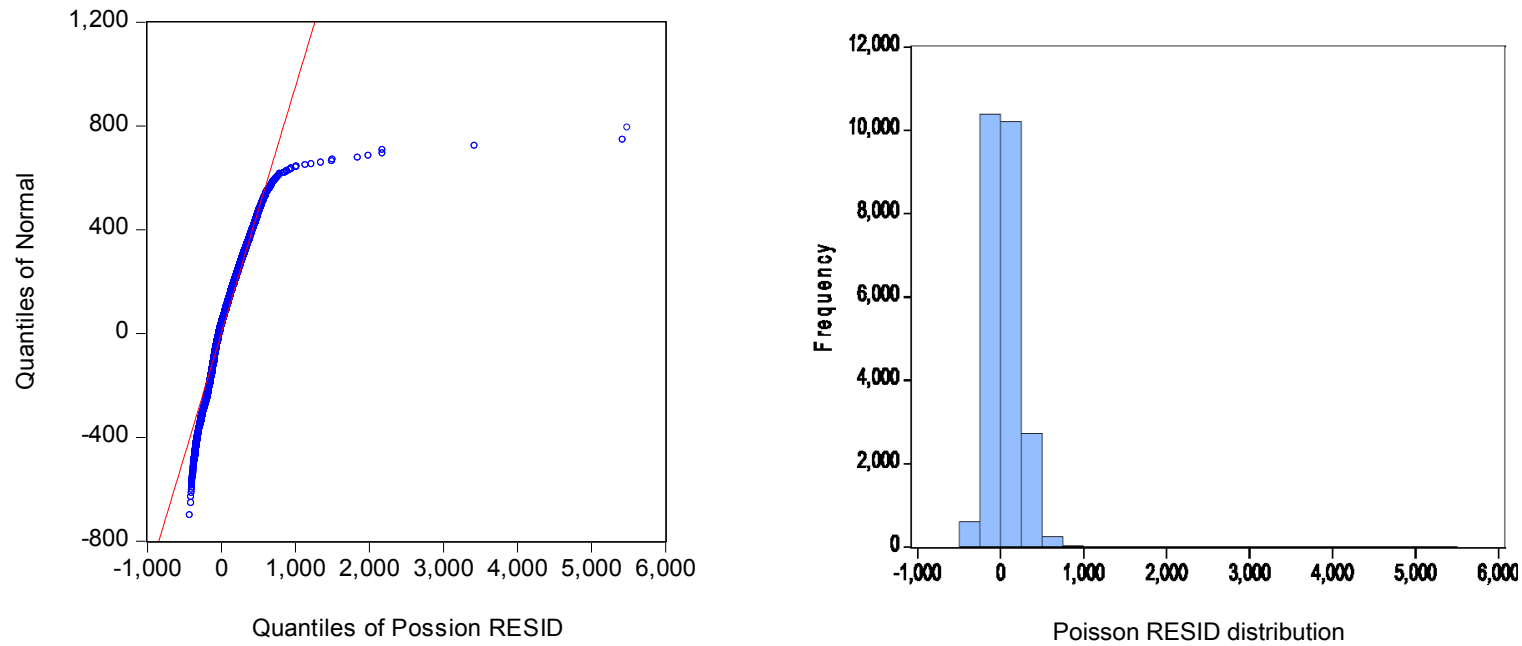

Figure 3a. Method: ML/QML - Poisson Count (Quadratic hill climbing)
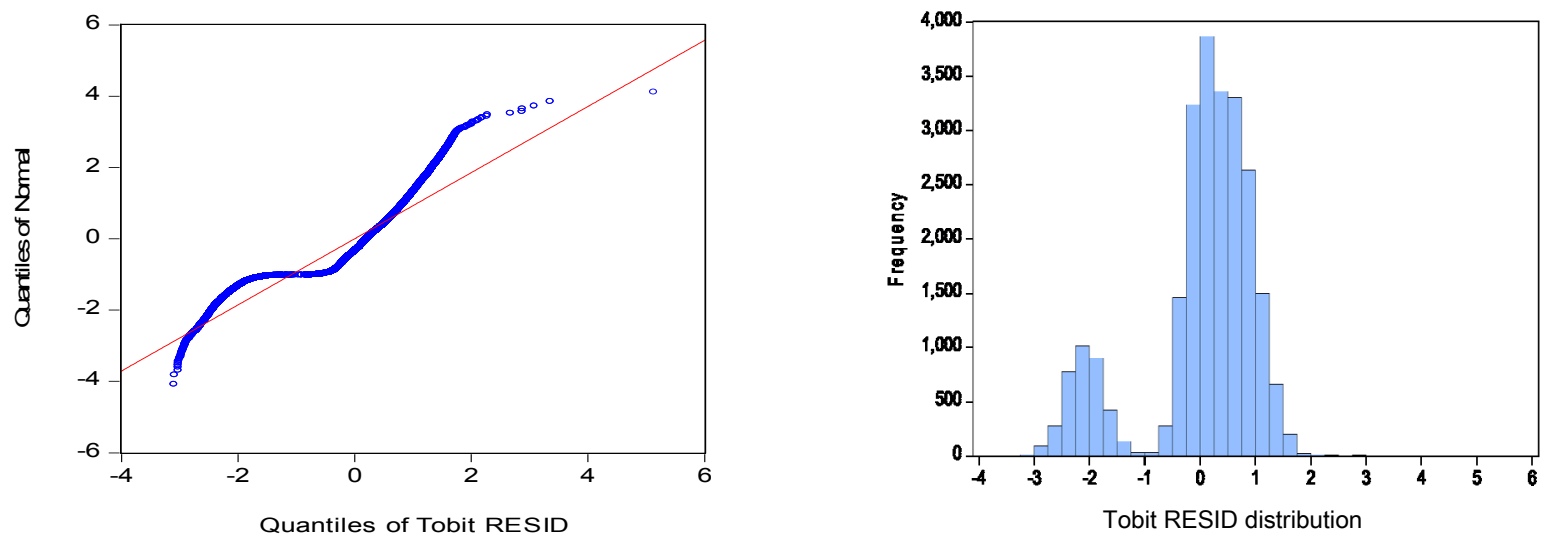

Figure 3b. Method: ML - Censored Normal (TOBIT) (Quadratic hill climbing)

Covariance matrix computed using second derivatives

Figure 3. Q-Q plot and Histogram of the residuals under Poisson and Tobit methodology

Period 2. (post 2007 i.e. after 2007)

The estimated Threshold-GARCH models can be found in Table 2. The estimated models show a distinct IGARCH effect: The estimates of $\alpha_{1}+\beta_{1}+\gamma_{1} / 2<1$ even not exceed unity. In a majority of cases, the asymmetry term $I_{t-1}=1$ dominates the term $\varepsilon_{t-1}^{2}$. Table 2 shows how the persistence measure $\alpha_{1}+\beta_{1}+\gamma_{1} / 2<1$ is dramatically smaller than 1 in all cases. For T-GARCH, the stationary condition under measure $P$, which is known to be $\alpha_{1}+\beta_{1}+$ $\gamma_{1} / 2<1$, Tables 2 also present the results using the empirical parameter estimates( ie. $\omega_{0}=2.88 \mathrm{e}-5 ; \beta_{1}=0.826 ; \alpha_{1}=$ 0.166 and $\gamma_{1}=-0.0183$ ) to $\alpha_{1}+\beta_{1}+\gamma_{1} / 2$ term. This parameter values imply a volatility persistence of 0.982 (ie. $\alpha_{1}$ $+\beta_{1}+\gamma_{1} / 2$ ) under measure $\mathcal{P}$. Threshold GARCH specification given by Eq. (1) implies that conditional volatility is a linear function of lagged conditional volatility and the square of the lagged value of a shock to the log return process. Substituting their estimated coefficient parameters into the general Eq. (5), we get the following value $\sigma_{H}$ $=0.182$ and 0.102 . What's the better capture the housing price volatility dynamics between Normal distribution (Marquardt) and generalized error distribution (GED). Figure 4 assesses the conditional normality assumption by 
plotting a Q-Q plot of residual against the normal distribution. Moreover, we also perform Q-Q Plot in Figure 4, and the Normal distribution also shows significant improvement with respect to the GED distribution. In this empirical work, we suggest that we perform to use Normal distribution rather than use GED distribution which gives a better fit to our data set. We may thus conclude that the GARCH-Normal model provides an important extension to the GARCH- GED model when it comes to option pricing. Then, the following simulation residual for fitted TARCH-Normal model in Figure 5. It is clear from Figure 5 that the TGARCH model does a good job of capturing the volatility dynamics in the monthly housing prices returns for single-family mortgages.

Table 2. Parameter estimates for housing prices log return under TGARCH process (Dependent Variable: DLOG (return))

\begin{tabular}{|c|c|c|c|c|}
\hline \multirow{2}{*}{$\begin{array}{l}\text { Panel (C) } \\
\text { parameter }\end{array}$} & \multicolumn{2}{|c|}{$\begin{array}{c}\text { TGARCH Normal } \\
\text { distribution(Marquardt) }\end{array}$} & \multicolumn{2}{|c|}{$\begin{array}{l}\text { TGARCH Generalized error } \\
\text { distribution (GED) }\end{array}$} \\
\hline & Coefficient & Prob. & Coefficient & Prob. \\
\hline $\mathrm{C}$ & $\begin{array}{c}0.005^{* * *} \\
(2.919)\end{array}$ & 0.0035 & $\begin{array}{l}0.003^{* *} \\
(2.443)\end{array}$ & 0.0145 \\
\hline \multicolumn{5}{|c|}{ Variance Equation } \\
\hline$\omega$ & $\begin{array}{c}2.88 \mathrm{E}-05^{* *} \\
(2.072)\end{array}$ & 0.0382 & $\begin{array}{c}3.81 \mathrm{E}-05^{* * *} \\
(1.507)\end{array}$ & 0.1316 \\
\hline$\alpha_{1}$ & $\begin{array}{l}0.166^{* * *} \\
(3.119)\end{array}$ & 0.0018 & $\begin{array}{c}0.064 \\
(1.3352)\end{array}$ & 0.1817 \\
\hline$\gamma_{1}$ & $\begin{array}{l}-0.0183 \\
(-0.221)\end{array}$ & 0.8255 & $\begin{array}{c}0.108 \\
(1.021)\end{array}$ & 0.3074 \\
\hline$\beta_{1}$ & $\begin{array}{l}0.826^{* * *} \\
(22.522)\end{array}$ & 0.000 & $\begin{array}{c}0.845^{* * *} \\
(14.7379)\end{array}$ & 0.000 \\
\hline$\alpha_{1}+\beta_{1}+\frac{\gamma_{1}}{2}$ & 0.982 & & 0.963 & \\
\hline$\sigma_{H}$ & 0.182 & & 0.102 & \\
\hline Log likelihood & 584.404 & & 590.265 & \\
\hline Akaike info criterion & -4.138 & & -4.1733 & \\
\hline GED parameter & & & $\begin{array}{l}1.367806^{* * *} \\
(8.914348)\end{array}$ & 0.0000 \\
\hline
\end{tabular}

Notes:

1. Values in parentheses denote $t$ values.

2. The table contains the parameter estimates from the TGARCH(1,1) model with Normal distribution(Marquardt) and Generalized error distribution (GED) for the housing prices for single-family mortgages returns, over the period September 29, 1998 - October 7, 2008. These estimates of Akaike info criterion and Log likelihood are in the same range as those found for the information content of the implied volatilities which examine information contend relative to GARCH and Exponential GARCH models of conditional volatility from call options on the S\&P 100 index by Day and Lewis (1992). 

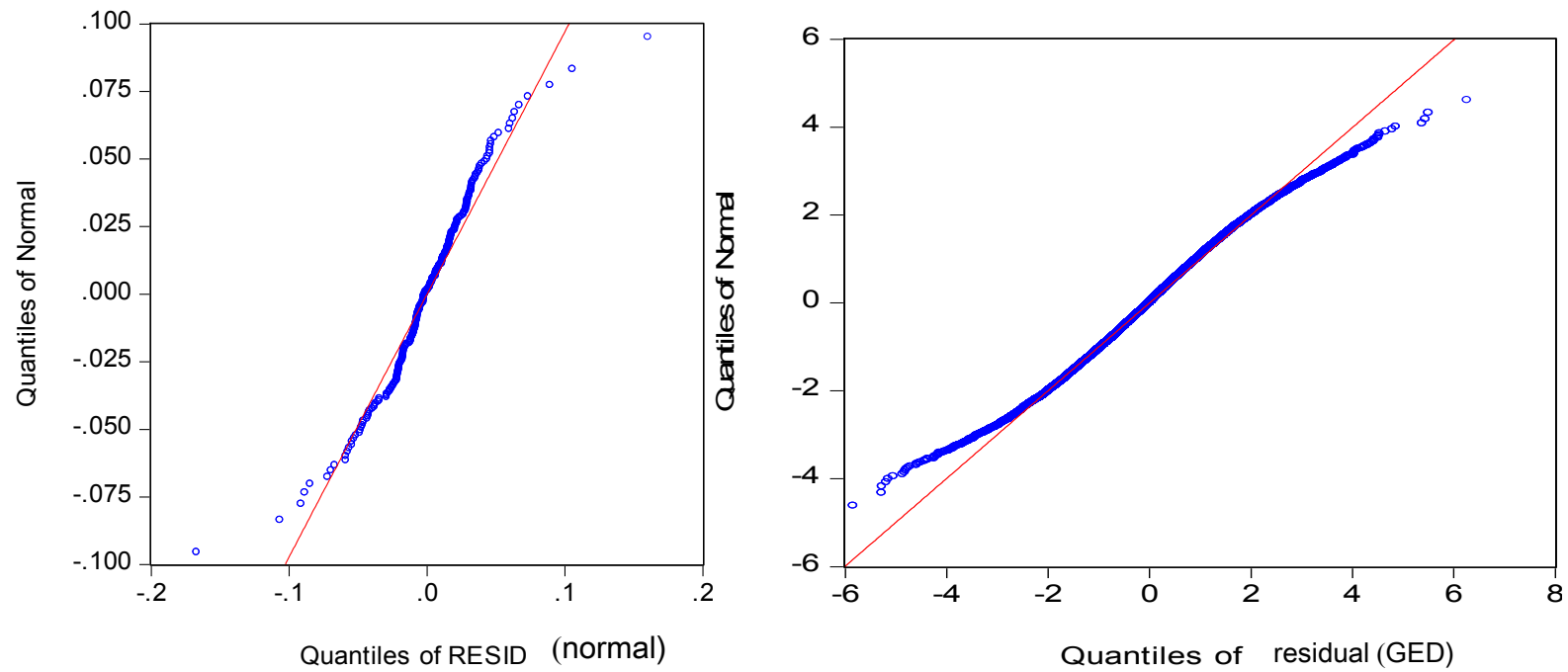

Figure 4. Quantile-Quantile plots of GARCH Innovations against the normal distribution

Notes to Figure: The quantiles of the standardized returns are plotted against the quantiles from the standard normal distribution. The quantiles of residual under normal distribution is more concentrated. more dispersion at General Error Distribution(GED).

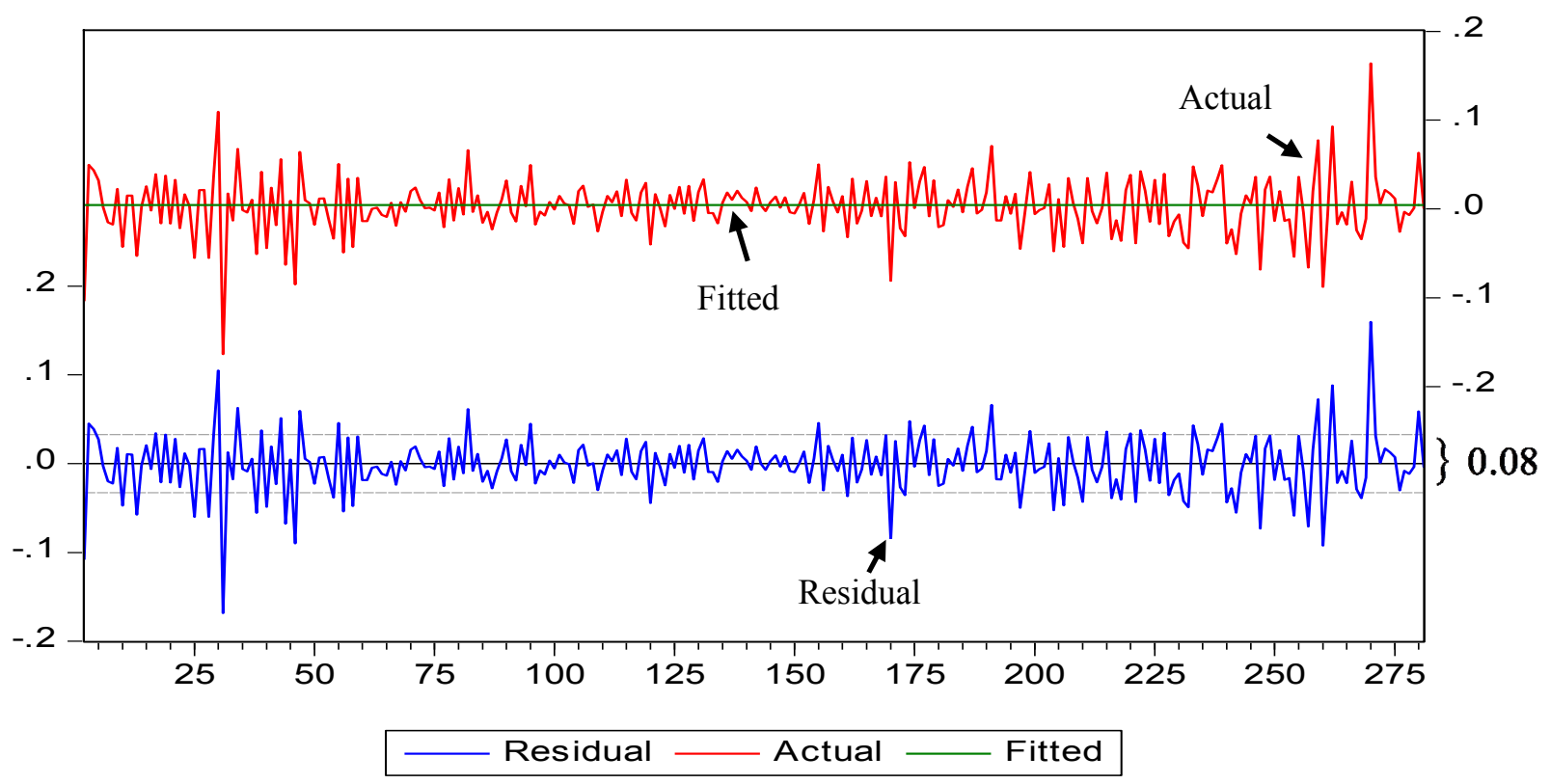

Figure 5. Comparison with the plot of actual and fitted value of $\log$ return

Notes to Figure: The residuals of fitted model situated within the scope of 0.08 .

\section{Conclusion}

As indicated by the booming U.S. property market sudden downturn, housing price depreciation risk is only partially diversifiable. The pooling mortgage products only partially reduce the diversifiable risk of a downturn in the regional housing market, but cannot diversify the collateral risk of a national economic depression. In recent years, demographic aging lead reverse mortgages to more popular in many countries. To solve the problem of cash poor and equity rich for elderly homeowners, reverse mortgage has been launched in developed countries such the U.S., the U.K. and Australia. The earlier models also assume house price returns follow normal error distribution. Unfortunately, house price returns in the study are potentially non-normal and asymmetric information. 
In this paper, the empirical results show that the numbers on RMs are positively associated with housing price, and initial principal limit, but are negatively associated with loan interest rate after 2007. We also construct the house price model via TGARCH with Normal distribution and generalized error distribution (GED-GARCH) pricing model under local risk-neutral valuation relationship (LRNVR). The approaches do significantly improve the financial institutions' ability to manage their risks and evaluate reverse mortgages. Through the study, it is benefit to determine the maximum level of lenders' margin and pricing reverse mortgage derivatives in the future.

\section{References}

Alai, D. H., Chen, H., Cho, D., Hanewald, K., \& Sherris, M. (2014). Developing Equity Release Markets: Risk Analysis for Reverse Mortgages and Home Reversions. North American Actuarial Journal, 18(1), 217-241. http://dx.doi.org/10.1080/10920277.2014.882252

Awartani, B.M.A., \& V. Corradi. (2005). Predicting the volatility of the S\&P-500 stock index via GARCH models: the role of asymmetries. International Journal of Forecasting, 21, 167-183. http://dx.doi.org/10.1016/j.ijforecast.2004.08.003

Case, K., \& Shiller R. (1989). The Efficiency of the Market for Single-Family Homes. American Economic Review, 79, 125-137. Retrieved from http://www.jstor.org/discover/10.2307/1804778?sid=21105354082141\&uid=3739216\&uid=70\&uid=2134\&uid $=2 \&$ uid $=4$

Chen, H., Cox, S.H., \& Wang, S.S. (2010). Is the Home Equity Conversion Mortgage in the United States sustainable? Evidence from pricing mortgage insurance premiums and non-recourse provisions using the conditional Esscher transform. Insurance: Mathematics and Economics, 46(2), 371-384. http://dx.doi.org/10.1016/j.insmatheco.2009.12.003

Crawford, G.W., \& Fratantoni M.C. (2003). Assessing the Forecasting Performance of Regime Switching, ARIMA and GARCH Models of House Prices. Real Estate Economics, 31, 223-244. http://dx.doi.org/10.1111/1540-6229.00064

Day, T., \& Lewis C. (1992). Stock Market Volatility and the Information Content of Stock Index Options. Journal of Econometrics, 52, 267-287. http://dx.doi.org/10.1016/0304-4076(92)90073-Z

Duan, J.-C. (1995). The GARCH Option Pricing Model. Mathematical Finance, 5, 13-32. http://dx.doi.org/10.1111/j.1467-9965.1995.tb00099.x

Duan, J.C., Gauthier, G., Sasseville, C., \& Simonato. J.G. (2006). Approximating the GJR-Garch and EGARCH Option Pricing Models Analytically. Journal of Computational Finance, 9, 41-69. Retrieved from http://quantlib.10058.n7.nabble.com/attachment/11808/0/jour_comp_fin_2.pdf

Greene, W. (2011). Econometric Analysis (7th ed.). Prentice Hall.

Hosty, G. M., Groves, S. J., Murray, C. A., \& Shah, M. (2008). Pricing and Risk Capital in the Equity Release Market. British Actuarial Journal, 14(1), 41-91. Retrieved from http://www.actuaries.org.uk/research-and-resources/documents/pricing-and-risk-capital-equity-release-market

Ji, M. (2011). A Semi-Markov Multiple State Model for Reverse Mortgage Terminations. Annals of Actuarial Science, 1(1), 1-23. http://dx.doi.org/10.1017/S1748499512000061

Lee, Y.T., Wang, C.W., \& Huang, H.C. (2012). On the Valuation of Reverse Mortgages with Regular Tenure Payments. Insurance: Mathematics and Economics, 51(2), 430-441. http://dx.doi.org/10.1016/j.insmatheco.2012.06.008

Li, J. S.H., Hardy, M., \& Tan, K. (2010). On Pricing and Hedging the No-Negative-Equity Guarantee in Equity Release Mechanisms. Journal of Risk and Insurance, 77(2), 499-522. http://dx.doi.org/10.1111/j.1539-6975.2009.01344.x

Lundbergh, S., \& Teräsvirta, T. (2002). Forecasting with Smooth Transition Autoregressive Models. In M.P. Clements and D.F. Hendry (Eds.), Companion to Economic Forecasting. Oxford: Black-well.

Merton, R. C. (1976). Option Pricing when the Underlying Stock Returns are Discontinuous. Journal of Financial Economics, 3, 125-144. http://dx.doi.org/10.1016/0304-405X (76)90022-2

Quercia, R. G. (1997). House Value Appreciation among Older Homeowners: Implications for Reverse Mortgage Programs. Journal of Housing Research, 8(2), 201-224. Retrieved from http://content.knowledgeplex.org/kp2/kp/text_document_summary/scholarly_article/relfiles/jhr_0802_quercia.p 
df

Shiller, R. J., \& Weiss, A. N. (1999). Home Equity Insurance. Journal of Real Estate Finance and Economics, 19, 21-47. http://dx.doi.org/10.1023/A:1007779229387

Winkelman, R. (2008). Econometric analysis of count data (Fifth ed.). Springer, BerlinHidelberg.

Zakoian, J.M. (1994). Threshold heteroskedastic models. Journal of Economic Dynamics and Control, 18, 931-955. http://dx.doi.org/10.1016/0165-1889 (94)90039-6

\section{Notes}

Note 1. Data is available from corresponding author upon request.

Note 2. Six types of payment options are available through RMs: lump sum, term, line of credit, modified term (which combines line of credit and term payments), tenure, and modified tenure (which combine tenure and line of credit). Of these, line of credit is the most popular payment option because of its high flexibility. However, RMs with tenure payments, such as the RAMs (reverse annuity mortgages), offer relief to social security systems.

Note 3. The distribution of the number of RMs loans is not shown in the content, its exhibit is available from the corresponding author upon request.

\section{Appendix}

Since $\sigma^{2}=E\left(\sigma_{t}^{2}\right)=E\left[\omega_{0}+\left(\alpha_{1}+\gamma_{1} I_{t-1}\right) \varepsilon_{t-1}^{2}+\beta_{1} \sigma_{t-1}^{2}\right]$ we get

$$
\omega_{0}+E\left[\sigma_{t-1}^{2}\right] E\left[\left(\alpha_{1}+\gamma_{1} I_{t-1}\right) v_{t-1}^{2}+\beta_{1}\right]
$$

$\left\{\sigma_{t-1}^{2}\right.$ is independent with the $\mathrm{t}-1$ period information, moreover, $\varepsilon_{t-1} / \Omega_{t-2} \sim N\left(0, \sigma_{t-1}^{2}\right)$,so $\varepsilon_{t-1}$ can be written as $\sigma_{t-1} v_{t-1}$, where $\left.v_{t-1} \sim N(0,1)\right\}$

Therefore, the eq. (A1) yields

$$
\begin{gathered}
\omega_{0}+E\left[\sigma_{t-1}^{2}\right]\left(\beta_{1}+\alpha_{1} E\left\lfloor v_{t-1}^{2}\right\rfloor+\gamma_{1} E\left[I_{t-1} v_{t-1}^{2}\right]\right) \\
=\omega_{0}+E\left[\sigma_{t-1}^{2}\right]\left(\alpha_{1}+\beta_{1}+\frac{\gamma_{1}}{2}\right)
\end{gathered}
$$

Since

$$
E\left[D_{t-1} v_{t-1}^{2}\right]=\int_{0}^{\infty} v_{t-1}^{2} \frac{1}{\sqrt{2 \pi}} e^{\frac{v_{t-1}^{2}}{2}} d v_{t-1}=\frac{1}{2} \int_{-\infty}^{\infty} v_{t-1}^{2} \frac{1}{\sqrt{2 \pi}} e^{\frac{v_{t-1}^{2}}{2}} d v_{t-1}=\frac{1}{2} E\left[v_{t-1}^{2}\right]=\frac{1}{2}
$$

Since this type is a steady process, so $E\left[\sigma_{t}^{2}\right]=E\left[\sigma_{t-1}^{2}\right], \forall \mathrm{t}=1,2$, .

Then the former equation can be written as

$$
\begin{gathered}
\Rightarrow \sigma^{2}=E\left[\sigma_{t}^{2}\right]=\omega_{0}+E\left[\sigma_{t}^{2}\right]\left(\alpha_{1}+\beta_{1}+\frac{\gamma_{1}}{2}\right) \\
\Rightarrow \omega_{0}=E\left[\sigma_{t}^{2}\right]-E\left[\sigma_{t}^{2}\right]\left(\alpha_{1}+\beta_{1}+\frac{\gamma_{1}}{2}\right) \\
\Rightarrow \sigma^{2}=E\left(\sigma_{t}^{2}\right)=\frac{\omega_{0}}{1-\left(\alpha_{1}+\beta_{1}+\frac{\gamma_{1}}{2}\right)}
\end{gathered}
$$

